\title{
Methodology for Optimizations of Business Processes in Macedonian Railways - Transport in the Republic of Macedonia
}

\author{
Elizabeta Mitreva, $\mathrm{PhD}^{1^{*}}$ \\ Elenior Nikolov, PhD2 \\ Biljana Nikolova, Msc. Cand² \\ Nako Taskov ${ }^{1}$ \\ PhD, Nikola Dimitrov ${ }^{1}$ \\ ${ }^{1}$ Faculty of Tourism and Business Logistics, University "Goce Delcev" - Shtip; Macedonia \\ 2Military Academy - Skopje, Macedonia \\ *Mail: elizabeta.mitreva@ugd.edu.mk; elizabeta.mitreva@gmail.com
}

Doi:10.5901/mjss.2016.v7n3s1p394

\begin{abstract}
To achieve success in applying the philosophy of TQM (Total Quality Management), managers of Macedonian Railways Transport must choose a certain methodology supported by a variety of methods and techniques. This paper analyzed the company Macedonian Railways - Transport with a view to identify whether it has an efficient system of quality by monitoring the way to manage business processes (identification, documentation and control) and whether it is built documentation for the Efficiency of the system. In railway traffic is necessary to observe railway standards, the standards for production, installation, service and transportation security of people and goods. To achieve the goals required and appropriate supervision. The opportunities provided by ISO 9000 standards allow us defining and activation of checkpoints, which will prevent defects, complaints, delays. But good quality system is not just a system that will provide the projected quality, but governance and optimization of the processes. For this purpose, when designing of the standard operating procedures, we need to apply an appropriate methodology for the methods and techniques for faultless production and methodology for optimizing the costs. In this paper, by applying the methodologies of Quick Response Quick Control; 8D (eight disciplines) and PFMEA method, the business processes in the Department of Revenue was optimized. The obtained results show that the implementation of these methodologies to optimize business processes leads to an improved quality and better productivity at the lowest costs of operation.
\end{abstract}

Keywords: Optimization of business processes, Quality system, Quick Response Quick Control (QRQC), 8D method, PFMEA method.

\section{Introduction}

The success of the application of the TQM (Total Quality Management) strategy depends on the managers' ability to choose a methodology supported by a variety of methods and techniques. A lot of organizational and technical factors affect the selection and application, so depending on the design, i.e. the organizational structuring of the quality system, classification of the faultless operation methods and techniques is proposed.

\section{Literature Review}

In the selection and application of methodologies for optimization of business processes affect a number of factors of organizational and technical character, and depending on the projecting or organizational structuring of the quality system can be proposed classification of the methods and techniques for faultless operation. Many scientists (Stoiljković V., Uzunović, R., Majstorović, V. et al., 1996) emphasize that the development of the methods and techniques for quality began with the first elements of statistical theory in the field of inspection, until today it has developed a dozen different techniques and tools of quality. They cite the example of the famous company Lucas Engineering \& Systems, where three of thirteen key principles for the development, implementation and success of the concept of total quality management are constituted principles related to methods and techniques of quality control, which talk about their 
important role. following:

The advantage of the application of methods and techniques of quality control in the companies are seen in the

- raising the level of quality in all business processes of the organization;

- reduction of all types of costs;

- reducing the cost of products;

- creation of trust among customers / users;

- raising the knowledge among employees.

In such manner it is achieved and increasing the motivation of employees, increase productivity, expanding markets. Based on the analysis that is made of enterprises engaged in metal working industry in the UK (Sohal et al., 1990) are coming to the conclusion that the biggest reasons due to which the enterprises do not use the methods and techniques of quality is ignorance and inexperience in applying them. They recommend overcoming these barriers by applying the methods and techniques of quality and their relevance in the application.

Through statistical process control (Juran 1978; Taguchi 1983; Deming, 1986) can be determined the stability and predictability of the processes in production. In addition, all variations can move in defined intervals, or in the limits of tolerance. If the process is a series of cases and conditions and a series of phases where expected the given value of input to give the required output with less variation in the output, then we can say that the process is stable (Stenberg and Deleryd, (1999).

For (Ebrahimpour et al., 1992), statistical process control is not just education, it is a strategy to reduce the variability as part of TQM strategy for permanent quality improvement (Oakland, 2000).

Statistical methods for quality control (Deming, 1986) are useful and have applications in many functions of the quality system, especially on the critical areas where improvement and optimization of business processes is necessary.

Although much of the statistical methods and techniques are used in productive enterprises, they have wide application in the service branches (Xie and Gho, (1999).

They help when deciding what data is important and how to extract maximum information from them, to avoid noncompliance, analysis of the current problems and others. (Ahire et al., 1996).

The statistical concept of quality management is characterized by four basic principles:

- the results of any process are variables, are shed and obey to any of the the laws of distribution;

- the mistakes are always possible and always present;

- the data always are collected, and based on them is undertaken corrective action;

- data must be presented with defined origin, for the manner of their acquisition, to be able to be used in right direction.

The scientists (Stenberg and Deleryd, (1999) based on their research study in 83 Swedish companies emphasize the benefits of the use of the statistical process control:

- achieving a low cost of quality and decreasing of losses;

- improvement of the business processes and products;

- better understanding of the processes;

- able to control the processes;

- quality assurance.

The application of TQM system methodology means designing a well-documented quality system that covers all business processes of the company and is the necessary basis for successful application of SPC (statistical process control) and efficient teamwork, which would not be possible in the case of a poor quality system.

\section{Methods in the Research and Analyses of the Results}

The projection and implementation of the system in TQM in Macedonian Railways - Transport is based on many pillars, and one of them is the internal standardization. The Standard Operating Procedures (SOPs) are intended to define the flows of all activities for each process and on that basis to define the obligations and responsibilities of each employee. The purpose of these standards is to unify the quality of work of all participants in an operation or process. When creating the SOP shall be incorporated experts knowledge of people, their experience and the ability for streamlining the processes. Thus, on the one hand is built the wealth of the company, on the other hand is created independence of each new employee from the experience of the previous (E. Mitreva, 2013).

The standard operating procedure serves as an instruction that allows employees to act without having to ask 
directions, and also the company can count on their employees because it is documented and can be easily measured their performance. The standard operating procedure must be accepted and adopted by employees and by the one who drew up or by the responsible manager. After completing the training the employees should say that they understand and accept the standard operating procedure.

In Figure 1 is given the standard operating procedure for business process in the department for control of revenue, which referred to the documents used in the process, the employees involved, and the possibility for comments with additional explanations or indicating the instructions that define the subprocess. The combination of QC-CE model of cause and effect gives the choice of the decision that defines the responsibilities of each employee in the service and improves collaboration among employees revealing their rules of conduct.
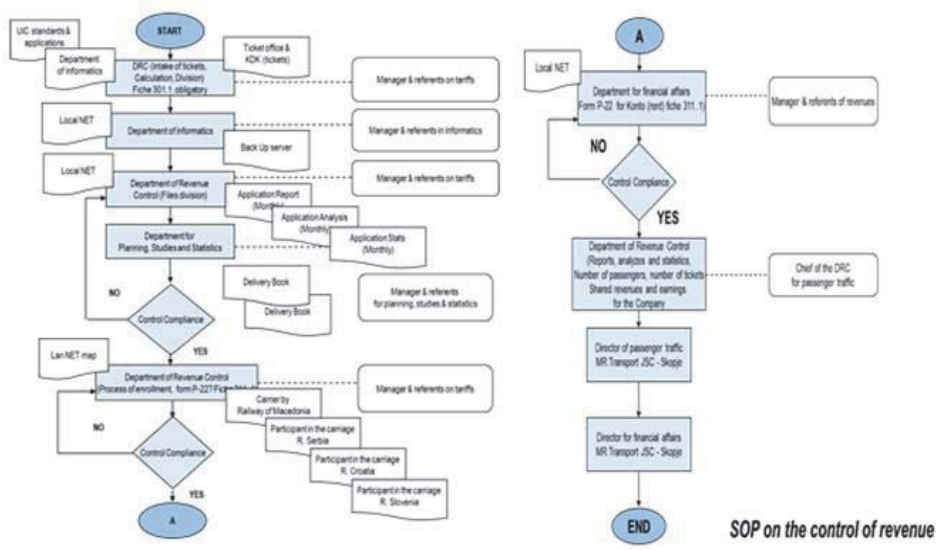

Figure 1: Standard operating process for revenue sharing other participating shipping

The application of internal standardization improves staff's familiarization with the implementation of business processes. When Deming's round will be installed in each function in the services for revenues control will reach the spiral of the quality, which can be explained with circular connection of all functions, where each function is accomplished with the defined quality. The spiral of the quality is base of an integrated management system of quality, which is introduced into every aspect of the service for revenue control and despite the variegated character of the business processes, fig. 2.

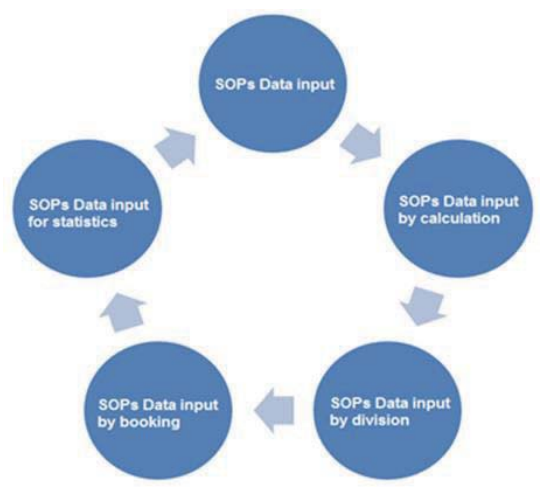

Figure 2: Spiral of quality for business processes in the service for revenues control

Good quality system is not just a system that will ensure the design quality, but management and optimize processes. For this purpose, when designing of the standard operating procedures, is applied an appropriate methodology for the methods and techniques for faultless production and methodology for optimizing the costs. 


\subsection{Analysis of the costs because of a delay}

In the Department of revenue control are monitored expenses on the basis of delay compensation the company Macedonian Railways - transport compensates to the railway company (a victim of the delay) due to caused additional costs. In actual processes in the department for revenue control for each accounting month data is entered from tickets and makes their processing. Further processing is taken by Department of Informatics over the LAN. The obtained results are stored in the so-called back up servers, which are further processed with other software applications and makes reports, statistics and analysis on a monthly, quarterly, semi-annually and annually. Department of revenue control gets ready files (excerpts, calculation, summary and reports for returned tickets - AIV etc.). These are electronically submitted by LAN network in the electronic form of mail (email) to other rail carriers (administrations), which are the exact stakes in assets (amounts) of tickets sold for their territories or tickets sold though their territory as staging rail (transit ). From the total amount of funds, $10 \%$ remain on Railway which sold the ticket due to manipulative fee. The rest of the amount should be divided to all participants in the shipping that is railways of Macedonia (starting station) transit carriers in this case Serbian and Croatian Railways and the reference on station Ljubljana or the stake to the Slovenian Railways.

Department of revenue control ie the head of the passenger majoring makes special reports in special patterns (Kp-39 reports, analyzes and statistics - number of passengers, number of tickets, shared revenues for Carriers (Kp-13) and revenues for our company) and submit them to the Director of passenger traffic.

Department of revenue control submits form R-22 to the financial department which gives the order/orders for payment of funds to Slovenia Railway and other railway companies involved in shipping. For all shared assets during the accounting month the DCR makes a report and forwards it to the Director of Financial Affairs of MZ Transport JSC Skopje. Calculation or division of revenues should be submitted in strictly defined deadline in the month. Each railway company whose delay the calculation or part of the calculation exceeds 5 working days is obliged to pay damages for each passing day, that default interest of each railway company (RU's) (participant in shipping). This satisfaction to on a daily basis is $1 \%$ of the gross amount or the share which is due to any company (the victim the delay), and therefore should be compensate the damage to same because of significant additional costs. If being late more than 15 working days, the Finance Committee of the International Union of Railways makes a decision on compensation for delays to the "great damage" and the rate of compensation is $5 \%$ on daily basis of the gross amount of the shares owed by the railway company to each railway Company (RU's) (participant in shipping). If the business process - "division of revenues" is done with 25 days delay, the Finance Committee of the International Union of Railways shall decide on an exceptional measure - liquidation the membership of the union. In that case the company must make individual transport contracts and with those activities is uncompetitive in the market. In Table 1 are given the cost on the basis of delay compensation, that the company Macedonian Railways - transport should compensates to railway company (a victim of the delay) due to caused additional costs.

Table 1: The cost on the basis of delay compensation

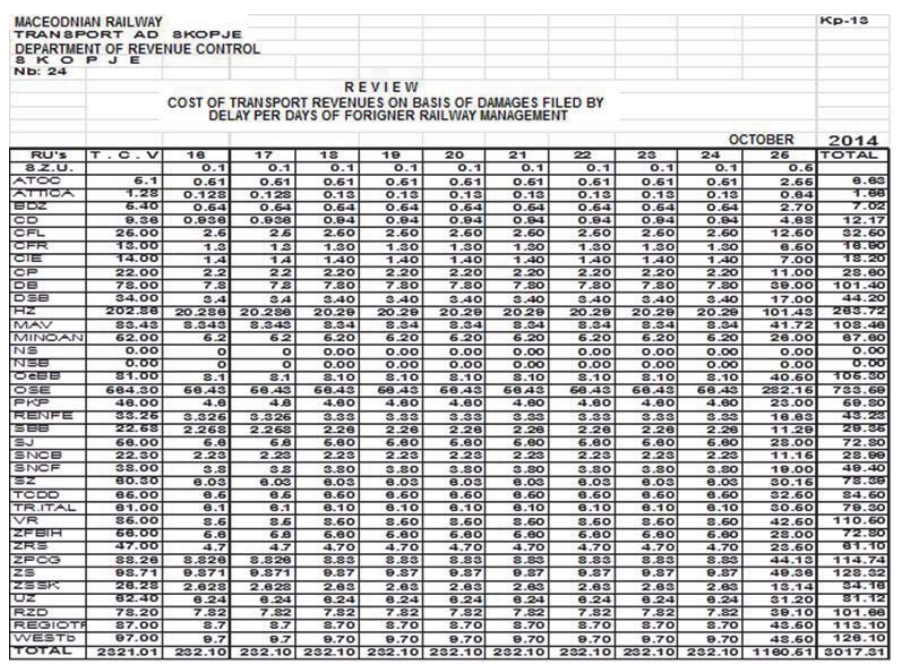


From the analysis in Table 1 can be seen all the losses that are made in Macedonian Railways - Transport based on compensation of delay calculation. To overcome these problems shall apply the methodology 8D (Eight Disciplines).

The applied methodology 8D (Eight Disciplines) was created by Ford to help the teams in companies to cope with the quality control and safety issues; to find adequate and lasting solutions to the problems; and to prevent recurrence of the problems. Although the process $8 \mathrm{D}$ is initially applied in the production, engineering and aerospace industries, it is useful and relevant to any industry. Correct operation from the first time does not make an additional cost. The trainings, training and the education of working teams or employees that contribute to reduce the cost of losses, mistakes, complaints.

Steps in the application of the methodology of the eight $D$ the Department of revenue control in Macedonian Railways - Transport are:

$>$ Step 1: It assembles a team to the particular problem of competent persons and in the case it is representatives from the Department of revenue control and representatives from the IT sector.

$>$ Step 2: It describes the problem - costs for damages filed by delay.

The Office for training concluded that there are shortcomings in the implementation of the program as the training and education of the employees for the real business process was carried on different computers, ie in the Department of Informatics and not in the Department of Revenue control (DRC). The testing of the program for entering teh revenues is made in the department of informatics by the engineers, and the cost of assessment or received statistical data (reports: CP - 13) showed solid results.

Applying the methodology of Quick response quality control (QRQC) for solving problems in Macedonian Railways - Transport on the basis of damages filed by delay for calculation is a tool for quick resolution no repetition the problems. It incorporates and Ishikawa diagram and 5Why method.

The application of the Quick Response Quality Control (QRQC) methodology is aimed at quick resolution of the products' quality control problems. This method of quick response to quality problems was introduced in Europe and France in the automotive industry in the early 2000s. Based on facts, the QRQC technique enables quick solution of problems in the workplace. This method is applied in reality at the site of the problem, thus avoids wasting time in meetings. In Department of Revenue Control (DRC) is applied the methodology of QRQC soon as appears the problem in the part of revenue intake, Table 2. The expert team included representatives from the Department of revenue control and IT department who first detected the problem . It has tallied the number of errors and determined the reasons. In this case they determined errors in Revenue intake, Table 2.

Table 2: Quick response quality control

\begin{tabular}{|c|c|c|c|c|}
\hline \multicolumn{5}{|c|}{ Quick response quality control (QRQC) Анализа } \\
\hline \multicolumn{5}{|c|}{ Errors in Revenue intake of railway tickets } \\
\hline QRQC & \multirow{2}{*}{\multicolumn{2}{|c|}{$\begin{array}{l}\text { Other members: } \\
\text { a referent - Katerina Risteska } \\
\text { information technologist - Suze Spasovska }\end{array}$}} & \multirow{2}{*}{\multicolumn{2}{|c|}{$\begin{array}{l}\text { Data: } 20150322 \\
\text { Number: } 62 / 1 / 2015 \\
\text { Recorded in Book of Procedures }\end{array}$}} \\
\hline Biljana Nikolova & & & & \\
\hline \multicolumn{3}{|c|}{ Problem Description: Matching deviations in intake of $\mathrm{km}$ and class } & $\begin{array}{c}\text { Research on source of } \\
\text { cause }\end{array}$ & Note \\
\hline \multirow{2}{*}{ 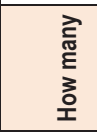 } & $\begin{array}{l}\text { How many deviations in } \\
\text { intake }\end{array}$ & 30 & & From 30 days \\
\hline & Frequency & On every $5^{\text {th }}$ intake & & Imported 824 tickets \\
\hline \multirow{2}{*}{$\sum_{\xi}^{\bar{\Xi}}$} & On beginning of intake & $\mathrm{km}$ & & \\
\hline & On the end of intake & class & & \\
\hline \multirow{2}{*}{ 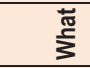 } & An accurate deviation & Identification class & & \\
\hline & An accurate reference & Identification of KM & & \\
\hline \multirow{2}{*}{$\begin{array}{l}\frac{\Phi}{\omega} \\
\frac{1}{\zeta}\end{array}$} & $\begin{array}{l}\text { On the beginning or on } \\
\text { the end }\end{array}$ & On every 5th intake & & \\
\hline & Location & Intake of class Intake km & & \\
\hline \multirow{3}{*}{$\stackrel{\circ}{\frac{0}{3}}$} & Training & 2 days & & \\
\hline & Education & High school & & \\
\hline & \multicolumn{2}{|c|}{ Action for the Protection of applications } & $\begin{array}{l}\text { Control of application } \\
\text { after each entry }\end{array}$ & Review $100 \%$ \\
\hline
\end{tabular}

Step 3: It takes a temporary solution. The process is blocked to prevent the further losses. 


\section{$>$ Step 4: To identify root of the problem.}

The determination of the causes does not stop here. It continues with using the method five - why (5-Way) to get to the causes of the problems. The activities that followed is proposing corrective measures that should be taken to never appear the same or similar problems. Finally followed the control after the application of corrective measures, Table 3.

Table 3: Verification of possible occurrences of errors

\begin{tabular}{|l|l|}
\hline Verification of possible occurrences of errors \\
\hline Most possible causes \\
\hline Why 1 & The application setting dislocated every 5th intake, makes control and writes control number instead input data \\
\hline Why 2 & $\begin{array}{l}\text { The beginning of the intake KM observes in computer application Control No. in the end of intake class - poor } \\
\text { voltage electricity UPS }\end{array}$ \\
\hline Why 3 & $\begin{array}{l}\text { Identification for class - in computer application writes Control No. } \\
\text { Identification for km - in computer application writes Control No. }\end{array}$ \\
\hline Why 4 & Computer application is set every 5th pressing to make the control or stored data - the wrong keys Enter \\
\hline Why 5 & Insufficient training for people with high school - 2 days \\
\hline
\end{tabular}

The Office for training made a two-day training of employees, and the positive test run from the statistical data from the -Department of Informatics persuades the computer engineers to install the applications from UIC into computers in the office of DRS service where actually is performed the business process. Because the business process that is executed in DRC has the appearance of errors after receiving the reports, business process occurs internal cost of purchasing unified printers, hardware programs or computers from a newer generation, stabilizers (UPS) to stabilize the mains voltage. Another problem that is found is the inappropriate temperature in the working premises where the computers are located (from $+35^{\circ} \mathrm{C}$ to $+42^{\circ} \mathrm{C}$ ) and causes errors in the process. Team that is working on the detection of the problem concluded that it is needed to increase the number of work days for staff training in the service of 10 days and reprogramming of command 5 that displays the number of control instead of intake data that cause further increases in internal costs. In external costs of the company are allocated the costs in accordance with the overdue days (1\% simple interest to 25 Day of delay), the submission of the reports on exactly the divided amounts for each member carrier - a participant in the carriage. According fiche 301.1 in article 2.4 the international transportation union has set deadlines for all businesses and it knows the deadline for processing the same. If it delays, is paying a penalty for delay of the country carrier (RU's) per days and, with that are appearing external costs.

$>$ Step 5: Formulated corrective measures:

- compliance of applications for intake of revenue between the Department of Information and The department of Revenue control (DRC);

- extended training of staff from the Department of revenue control (DRC);

- purchase of air conditioners for optimum working conditions for the employees and technology.

$>$ Step 6: Implementation and verification of the corrective measures. The corrective measures are applied in practice.

Step 7: To prevent the problem of re-appeared in the department of revenue control are frequently performing a check.

$>$ Step 8: In the end congratulations for the employees who were involved in the project and the project is closed.

The proposed improvement of the existing information system where all functions in the office are computer-related with, now can be important in improving efficiency - it is checked in the practice.

The methodology of the Process Failure Mode Effects Analysis (PFMEA) is used by an organization, business unit, or cross-functional team to identify and assess possible flaws of a process. PFMEA helps to determine what will be the impact of a failure on a process to give priority to actions in order to mitigate the risk. FMEA analysis begins before you start the process (or product) and maintain and modify if necessary throughout the entire life cycle of the process (product).

Steps in application of the methodology of PFMEA in the railway traffic in Macedonia are following:

1. Establishing a cross - functional team of the process holders and the personnel that supports the business process and appointed team leader.

2. The team leader defines the scope, objectives and timeframe for completion of the project PFMEA.

3. The team creates a detailed process map. 
4. The team evaluates the the severity, frequency and probability of detection of errors for each step in the process.

5. Based on RPN value, are identified the required corrective actions for each step of the process.

6. It is proposed scheme for corrective measures.

7. Team - leader periodically checks the status of corrective actions and update project PFMEA.

8. The team leader also follows the changes in the process, changes in design, and other critical changes and updates RFMEA project.

9. Team Leader organize periodic meetings to review the implementation of the project RFMEA (quarterly review may be one of the options).

PFMEA analysis is used for the systematic analysis of the failure and the identification of the effects on the system operation. The benefits of this analysis are: documented method for selecting a service or product with a high probability of success; early identification of a problem; effective method from choosing a product or service and provides criteria for planning tests. The same is done with 10 steps and they are:

$>$ process review (given on Fig.1);

$>$ "storm of thoughts' assumptions about possible errors;

$>$ a list of consequences of possible mistakes;

$>$ ranking the seriousness of the errors;

$>$ ranking the frequency of errors;

$>$ ranking the probability of errors;

$>$ calculation of RPN (number of priority);

$>$ development of an action plan (responsibilities - who, what, when, where);

$>$ enforcement action.

Brainstorming conditions are listed by teams from different departments to detect errors because of the reasons these errors have occurred, ie It requires root cause. In Step 2 of the analysis are shown a few flaws that business process makes mistakes, such as:

- error from referents (habitually pressed keys Enter, instead of Ctrl);

- error of information technologist (on ordinance should have 5,, intake data,, and there are a number of control or "control number"

- error on the computer - from weak voltage electricity;

- error in the program - non-uniform hardware programs of Windows 2007 and 2010;

- error from employees - insufficient training of 2 days;

- error on printer - non-uniform roll papers and A4;

- error on the computer - from operating temperature to $+42^{\circ} \mathrm{C}$; etc.

The ranking of the seriousness, frequency and probability is made from 1 to 10 . All of them are multiplying and gets the number of priority RPN. From the number RPN the priority is seen and from where should be the fastest start for solving the problem of reducing the errors to zero or to follow the action plan. After implementation of the action plan, the business process "data entry" repeats itself and with received reports does repeated calculation for obtaining the number of priority RPN, Table 4. 
Table 4: Application of the PFMEA methodology in the revenue intake and analysis of failure modalities and causes of failure

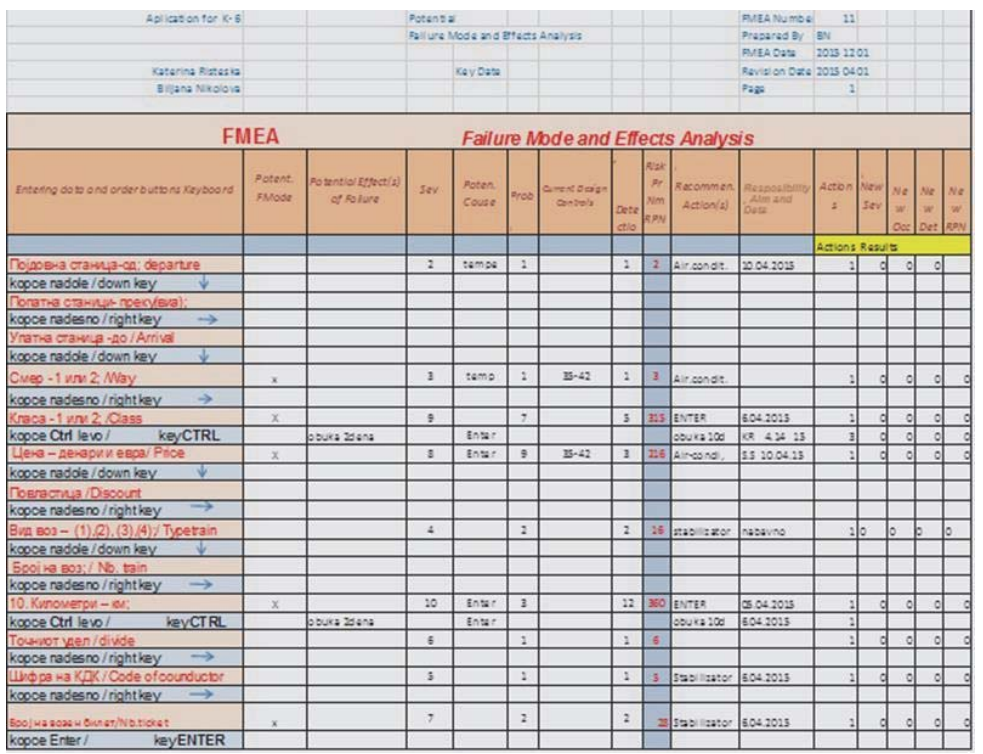

The displayed PFMEA analysis is made by the responsible managers before proceeding with the business process. The results, ranked according to the severity, frequency, and probability, after correcting every cause of error are shown in Table 5.

Table 5: Analysis of the modalities of failure and cause of failure

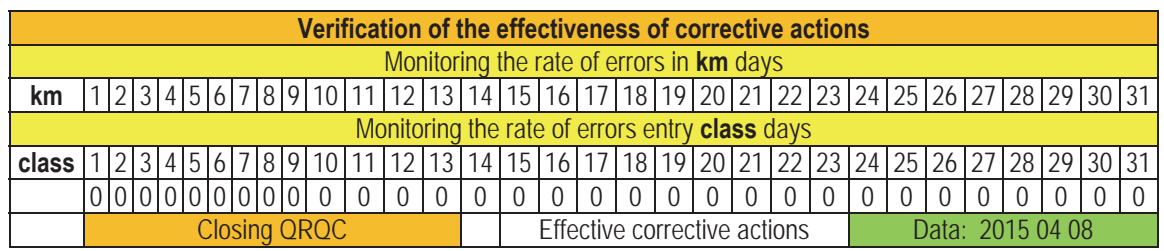

\section{Conclusion}

The application of methodologies for cost optimization have shown that they are very important for the management as they allow achieving the defined quality, with the smallest defects and loss expenses. From the research we made we can extract the following conclusions:

1. With the application of QC-CE (Quality Cycle \& Cause and Effect) model be manageable all business processes in the Macedonian Railways - Transport in a way that accurately will be determined the obligations and responsibilities of all participants in the planning, implementation, controlling and correcting. With this methodology is projected the standard operating procedures for all business processes in Office for revenue control like a good upgrade to the requirements of ISO 9001.

2. Proposed methodology for cost analysis that covers several methods: the Quick Response Quick Control; 8D (eight disciplines) and PFMEA method. The application of this methodology has shown that it is very useful for the management because it allows achieving the defined quality in the smallest defects and loss expenses. The information system is fundamental to the quality assurance system. The proposed improvement of the existing information system where all functions in certain departments in the company are computer-related, 
may be significant performance improvement, but it should be checked in practice.

3. These methods and techniques for faultless operation in the railway traffic have enabled to achieve the defined quality of service, to protect consumers from poor quality, and thus increased the company's competitiveness, profitability, improve quality, and decreased the defects and the costs in the operation, increased satisfaction and employee participation in decision-making. This points to the fact of the universal application of these methodologies in practice, regardless of branch companies belong to.

\section{References}

Mitreva, E. (2011). Model-integral methodology for successful designing and implementing of TQM system in Macedonian companies. International Journal for Quality Research, 5(4). pp. 255-260.

Mitreva, E., Taskov, N., Kitanov, V., Filiposki, O. \& Boskov, T. (2013a). The Need for Information System Design in Building a House of Quality. International Journal of Pure and Applied Sciences and Technology, 16(1). pp. 26-33.

Mitreva, E. \& Chepujnoska, V. (2007). Application of the Total Quality Management concept (TQM) in managing company's information, Economic development, Skopje, 9(3). pp. 297.

Mitreva, E., Taskov, N. \& Lazarovski, Z. (2014a). The need for the design and implementation of TQM system for the airport services TAV Airports Holding, Macedonia. In: 8th International Quality Conference, 23 May 2014, 8th IQC, Center for Quality, Faculty of Engineering, University of Kragujevac.

Mitreva, E., Taskov, N. \& Crnkovic, S. (2014b). Application of methodology for business process improvement in specialized diagnostic laboratory. Quality - Access to Success, 15(141), pp. 91-95.

Mitreva, E. (2013b). "The superior customer's value of the new economy implemented within Macedonian companies." International Journal for Quality Research 7(2). pp. 215-220.

Arsovski, S. (2002). "Menagement of quality ekonomic", Kragujevac.

Oakland, J. S. (2000). Total quality management -Text with cases, 2nd edition, Butterworth Heinemann.

Beskese, A. \& Cebeci, U. (2001). Total quality management and ISO 9000 applications in Turkey, The TQM Magazine, 13(1). pp. 69-73.

Casadesus, M., \& Gimenez, G. (2000). The benefits of the implementation of the ISO 9000 standard: empirical research in 288 Spanish companies, The TQM Magazine, 12(6). pp. 432-441.

Mitreva, E. \& Prodanovska V. (2013). The Management Teams are a Unique Business Potential that can Initiate, Identify and Manage Change within the Organization. In: Applied Social Sciences: Administration and Management.Cambridge Scholars Publishing, Newcastle upon Tyne, UK, pp. 57-65.

Chepujnoska, V. \& Mitreva, E. (2008). Methodology for optimization of the quality costs, Economic development, Skopje, 10(1). pp. 213.

Mitreva, E., Taskov, N., Sazdova, J., Gjeorgieva, I. \& Gjorshevski, H. (2015a). The Need for Implementation of Integrated Management Systems (IMS) in Macedonian Companies. Calitatea - acces la succes (Quality - Access to Success), 16(147). pp. 62-65.

Mitreva, E., Taskov, N. \& Angeleski, M. (2015b). Approaches for the Advancement of Business Processes in a Company that Deals with Graphic Production. Actual Problems of Economics, 6 (168). pp. 190-201.

Stoiljković, V., Uzunović, R. \& V. Majstorović, V. (1996). Q-tools, CIM College, The Faculty of Engineering Nis, www.CIMCollege.co. yu/QMS.

Taguchi, D. (1983). Clausing, Robust quality. Harvard Business Review, 64(4). pp. 65-75.

Deming, W. E. (1996). Kako izaći iz krize, PS Grmeč, Beograd, pp. 30.

Kanji, G. K. (1998b). An innovative approach to make ISO 9000 standards more effective, Total Quality Management, 9(1). pp. 67-78.

Nakata, Ch. (2002). Activating the marketing concept in a global context: An MNC country managers' perspective, International Marketing Review, 19(1). pp. 39-64.

Prodanovska, V. \& Mitreva, E., (2012). Incorporation, authorization and encouragement of the employees in order to improve the quality of the educational process. In: Two decades of academic teaching, 18-19 June; Timisoara.

Sohal, S. A., Abed, H. M. \& Keller, Z. A. (1990). Quality assurance: Status, structure and activities in manufacturing sector in the United Kingdom, Quality Forum, 16(1). pp. 38-49.

Stenberg, M. (1999). Implementation of statistical process control and process capability studies: requirements or free will? Total Quality Management, 10(4-5). pp. 439-446.

Taguchi, G. \& Clausing, D. (1983). Robust quality. Harvard Business Review, 64(4). pp. 65-75. 